\title{
AVALIAÇÃO QUANTITATIVA DO USO DOS RECURSOS HÍDRICOS EM UNIDADE DE CONSERVAÇÃO: ESTUDO DE CASO DO PARQUE ESTADUAL SERRA DO MAR
}

\section{Quantitative evaluation of the use of water resources in protected area: Case study of the Serra Mar State Park}

\author{
Roberto Starzynski \\ Instituto Florestal, São Paulo, São Paulo, Brasil \\ rostarzynski@hotmail.com
}

Silvio Jorge Simões Universidade Estadual Paulista, Guaratinguetá, São Paulo, Brasil silvio.jorge.simoes@gmail.com

Artigo recebido em 06/05/2014 e aceito para publicação em 29/09/2015

RESUMO: Este trabalho é um estudo de caso sobre o serviço ambiental hídrico prestado pelo Parque Estadual da Serra do Mar (PESM) ao promover a regularização dos mananciais e garantir o suprimento de água para adensadas regiões urbanas do Estado de São Paulo. Foi realizado através da análise de dados populacionais e de outorga de água na região de estudo, com o objetivo de avaliar a pressão antrópica, quantificar o volume de água outorgado, bem como identificar as principais categorias de usuários. Ressalta a importância do estabelecimento de uma política de Pagamento por Serviços Ambientais (PSA) que venha a aumentar a dotação orçamentária da Unidade de Conservação (UC) e consequentemente as ações de proteção ao ambiente natural. Os dados demográficos mostram que o entorno do PESM apresenta grande população e elevadas taxas de crescimento anual, fato que configura uma grande pressão sobre a UC, especialmente sobre seus recursos hídricos. Constatou-se que o volume total de água outorgado é de $752.305 .722 \mathrm{~m}^{3} /$ ano sendo que o Abastecimento público é a categoria que apresenta o maior volume $(64,40 \%)$, seguido pelo Uso industrial (29,58\%). A análise dos volumes totais outorgados mostra também que $99,09 \%$ da água é captada superficialmente e apenas 0,91\% captada de forma subterrânea.

Palavras chave: Parque Estadual da Serra do Mar. Serviço ambiental hídrico. Pagamento por Serviços Ambientais.

ABSTRACT: This paper is a case study on water environmental service provided by the Serra do Mar State Park (PESM) to promote the regularization of water sources and ensure the supply of water to densely populated urban areas of the São Paulo State. Was performed by analyzing population data and granting of water in the study region, with the aim of evaluating the anthropogenic pressure, quantify the volume of water granted, as well as to identify major categories of users. Underscores the importance of establishing a policy of Payment for Ecosystem Services (PES) that will increase the budget allocation of the protected area and consequently the protective actions to the natural environment. Demographic data show that around the PESM has large population and high rates of annual growth, a fact that sets up a lot of pressure on the protected area, especially on its water resources. It was found that the total volume of water granted is $752,305,722 \mathrm{~m} 3 /$ year being that the public supply is the category with the largest volume (64.40\%), followed by industrial use $(29.58 \%$ ). The analysis of the total awarded volumes also shows that $99.09 \%$ of the surface water is captured and only $0.91 \%$ of groundwater-abstracted form.

Key words: Serra do Mar State Park. Water environmental service. Payments for Ecosystem Services.

DOI: http://dx.doi.org/10.1590/1982-451320150210 


\section{INTRODUÇÃOO}

As UCs são criadas com o objetivo de preservar o patrimônio natural, cultural bem como as belezas cênicas e prestam uma série de serviços ambientais para a sociedade (BRAGA et al, 2002). A qualidade e continuidade destes serviços dependem da integridade do ambiente o que por sua vez está relacionado aos esforços empregados na proteção. Em função dos altos custos da proteção, em maioria arcados pelo Estado, que tem o dever constitucional de exercer este papel, torna-se altamente desejável a participação da sociedade como coadjuvante no processo.

Diversos autores colocam que o Pagamento por Serviços Ambientais (PSA) é um conceito que vem se firmando ao longo das últimas décadas, da mesma forma que o princípio do Protetor-Recebedor e desenvolveram trabalhos de valoração dos serviços ambientais prestados (VINICIO, 1998; SANTOS et al, 2001; ALBIZU et al, 2008; FEEL e TREMÉA, 2008; POLANCO et al, 2010; FLORES et al, 2010; HUPFFER et al, 2011). Embora prevista na legislação federal através do Artigo 47 da Lei $\mathrm{N}^{\circ} 9.985$ (BRASIL, 2000) e na legislação estadual, através do Artigo 32 do Decreto 60.302 (SÃO PAULO, 2014), a contribuição financeira às unidades de conservação produtoras de água, por parte de seus usuários, ainda não está implantada. A valoração do serviço hídrico e os procedimentos metodológicos necessários para a sua efetivação carecem ainda de análises e estudos.

O PESM procura promover a proteção e a conservação da biodiversidade e das belezas cênicas além de propiciar espaços para recreação, lazer, visitação pública e educação ambiental (SÃO PAULO, 1977). Os serviços ambientais prestados pelo PESM são significativos, especialmente nos núcleos urbanos localizados em seu entorno propiciando diversos aspectos positivos: ameniza o clima, oferece a estabilização das encostas, dando melhor proteção aos moradores de áreas críticas, e regula o fluxo dos mananciais garantindo o suprimento de água em aspectos quantitativos e qualitativos.

Este trabalho é um estudo de caso sobre o serviço ambiental hídrico prestado pelo PESM ao promover a regularização hídrica e garantir o suprimento de água para adensadas regiões urbanas do Estado como a Baixada Santista e o Litoral Norte. Foi realizado através da análise de dados populacionais e de outorga de água na região de estudo, com o objetivo de avaliar a pressão antrópica, quantificar o volume de água outorgado, bem como identificar as principais categorias de usuários. A avaliação quantitativa realizada poderá ser utilizada para subsidiar a implantação de mecanismos de compensação financeira, pelo serviço ambiental hídrico prestado pelo PESM.

\section{Revisão Bibliográfica}

A Lei no 7.663/91 (SÃO PAULO, 1991), que estabeleceu normas de orientação à Política Estadual de Recursos Hídricos, reconhece os recursos hídricos como um bem público tendo valor econômico e cuja utilização deve ser cobrada. Esta lei adota a bacia hidrográfica como unidade físico-territorial de planejamento e gerenciamento descentralizado, participativo e integrado, bem como define a compatibilização do gerenciamento dos recursos hídricos com o desenvolvimento regional e com a proteção do meio ambiente. Em seguida, a Lei 9.034/94 (SÃO PAULO, 1994) aprovou a divisão do Estado de São Paulo em 22 (vinte e duas) Unidades Hidrográficas de Gerenciamento de Recursos Hídricos (UGRHI).

A Lei $\mathrm{N}^{\circ}$ 9.985/2000 (BRASIL, 2000), que instituiu o Sistema Nacional de Unidades de Conservação da Natureza (SNUC), define unidade de conservação como sendo o espaço territorial e seus recursos ambientais, incluindo as águas jurisdicionais, legalmente instituído pelo Poder Público, com objetivos de conservação e limites definidos, sob regime especial de administração, ao qual se aplicam garantias adequadas de proteção; através do seu Artigo 47 criou a obrigatoriedade de contribuição financeira para as unidades de conservação por parte de empresas responsáveis pelo abastecimento de água ou que façam uso de recursos hídricos provenientes de unidades de conservação. Entretanto, o Artigo 47 desta lei ainda não foi regulamentado e a mencionada contribuição financeira ainda não está 
sendo realizada. A mesma lei prega a necessidade de existir uma Zona de Amortecimento (ZA), definida como o entorno de uma unidade de conservação, onde as atividades humanas estão sujeitas a normas e restrições específicas, com o propósito de minimizar os impactos negativos sobre a unidade. No Brasil também são comumente usados os termos "zona tampão" ou "zona de entorno" para se designar a ZA, enquanto que na esfera internacional é utilizado o termo buffer zone. Internacionalmente, o termo Protected Areas é comumente empregado para definir as unidades de conservação (WWF 2008).

A importância das unidades de conservação da natureza tem sido ressaltada pela amplitude de benefícios que proporciona ao manter a cobertura florestal. BRAGAetal (2002) apresentam os múltiplos serviços ambientais da floresta considerando os serviços hídricos, a conservação da biodiversidade, ciclagemdenutrientes, controle da erosão, amenização climática, retenção de carbono, além dos serviços proporcionados pela manutenção da paisagem que incluem atividades antrópicas de contato com a natureza e a educação ambiental. Segundo Lima (1986), a cobertura florestal influi positivamente sobre a hidrologia no solo, melhorando os processos de infiltração, percolação e armazenamento de água, além de diminuir o escoamento superficial.

Inúmeros trabalhos de hidrologia florestal, que auxiliaram no entendimento do papel da Floresta Atlântica na conservação dos recursos hídricos, foram realizados no Laboratório de Hidrologia Florestal Eng. ${ }^{\circ}$ Agr. ${ }^{\circ}$ Walter Emmerich localizado no Núcleo Cunha do PESM. Cicco et al (1986), estudando pelo período de um ano a interceptação das chuvas pelas copas das árvores em floresta natural secundária mediram as porcentagens, em relação à precipitação total, da precipitação interna, escoamento pelo tronco e interceptação sendo que os valores encontrados foram $80,65 \%, 1,12 \%$ e $18,23 \%$ respectivamente. Carvalho et al (1992), estudando as propriedades físicas de solos de microbacia experimental constatou que as porosidades dos horizontes $\mathrm{A}$ e $\mathrm{B}$ são respectivamente $59,1 \%$ e $44,2 \%$ sendo, ainda, alta a permeabilidade destes horizontes. Arcova (1996), comparando o balanço hídrico e características do deflúvio constatou que as microbacias experimentais
B e D do referido Laboratório são conservativas quanto ao consumo de água e que a evapotranspiração anual da vegetação de Mata Atlântica ocorre a taxas consideravelmente menores que outras florestas de clima tropical; constatou também que as microbacias apresentam um regime de vazão bastante regular ao longo do ano, sendo que a produção hídrica no período das chuvas supera em apenas $10 \%$ a produção no período mais seco. Fujieda et al. (1997), analisando dados hidrológicos das microbacias experimentais do PESM - Núcleo Cunha utilizou a equação do balanço hídrico e verificou que $70 \%$ da precipitação gera deflúvio e $30 \%$ sofre evapotranspiração. Estes estudos revelam a característica hídrica conservativa da Floresta Atlântica, ecossistema dominante no PESM.

Arcova e Cicco (1999), avaliando a qualidade da água com diferentes usos de solo na região de Cunha - SP (agricultura, pecuária extensiva e vegetação de Mata Atlântica) constataram que a temperatura, turbidez e cor aparente da água nas bacias com agricultura tiveram valores superiores aos registrados nas microbacias florestadas.

Honda et al (2002) monitoraram por 41 meses a concentração de sedimentos em suspensão nas águas dos rios Paraibuna e Paraitinga, cujas bacias hidrográficas apresentam grande variação no uso do solo. Nos quatro pontos amostrados, sendo dois pontos em cada rio, um no terço superior e outro a jusante, constataram que os valores médios das concentrações nos rios Paraibuna e Paraitinga foram de, respectivamente, $17,2 \mathrm{mg} / 1$ e $45,8 \mathrm{mg} / 1 \mathrm{no}$ terço superior dos rios, e de $11,6 \mathrm{mg} / 1$ e $57,3 \mathrm{mg} / 1$ a jusante na mesma ordem. Concluíram que as altas concentrações de material particulado encontradas no rio Paraitinga refletem o uso do solo desta bacia, ocupado extensamente por pastagens, na sua maioria em processo de degradação, enquanto que na bacia do rio Paraibuna o solo está melhor protegido por remanescentes de floresta natural.

Benefícios econômicos da proteção florestal também são percebidos no tratamento da água para consumo humano. Reis (2004) determinou os custos, para o ano base de 2002, do tratamento da água proveniente de sete bacias hidrográficas com diversos percentuais de cobertura florestal e verificou que o 
valor gasto com produtos químicos nas Estações de Tratamento eleva-se com a redução do percentual de cobertura florestal na bacia de abastecimento. Nos casos extremos encontrados, verificou-se que, na Estação de Tratamento de Água (ETA), que capta água do rio Piracicaba, em bacia hidrográfica com $4,30 \%$ de cobertura florestal, o custo específico dos produtos químicos utilizados no tratamento era de $\mathrm{R} \$ 92,61$ para $1.000 \mathrm{~m}^{3}$ tratados, enquanto que na ETA que abastece a Região Metropolitana de São Paulo e capta água do Sistema Cantareira, cuja bacia hidrográfica apresenta 27,16\% de cobertura florestal, o custo específico dos produtos químicos era de R\$ $7,20 / 1.000 \mathrm{~m}^{3}$.

O Pagamento por Serviços Ambientais (PSA) é uma ferramenta para promover a conservação dos recursos naturais utilizada em todo o mundo (VINICIO, 1998) e surgiu na Costa Rica como um mecanismo para reduzir a significativa degradação ambiental naquele país.

Segundo Hupffer et al (2011), os instrumentos jurídicos clássicos não conseguem alcançar o nível de complexidade das questões ambientais atuais em função da constatação de que, para a efetiva tutela do ambiente, a cobrança de taxa de quem polui ou degrada o meio ambiente (princípio do poluidor-pagador) não é suficiente, sendo necessária a utilização de instrumentos promocionais, a partir do princípio da precaução, que possibilita sustentação ao pagamento ou compensação por serviços ambientais prestados; assim, essa realidade precisa ser compreendida e assimilada sistemicamente para que o Direito possa construir mecanismos capazes de viabilizar a implementação de programas que promovam o princípio do protetor-recebedor e programas de PSA.

Feel e Treméa (2008), discutindo o Princípio do Protetor-Recebedor colocam que a compensação por serviços ambientais prestados é uma questão de justiça econômica, compensando quem age a favor da natureza e punindo quem a polui; este novo instrumento deve ser aperfeiçoado e posto a disposição da proteção ambiental, mas encontra barreiras como a carência de políticas públicas que incentivem tais práticas, a falta de um mecanismo estável e duradouro de financiamento e de uma base legal que reconheça o valor econômico dos serviços ambientais.

A Lei No 12.183/2005 (SÃO PAULO, 2005), dispõe sobre a cobrança pela utilização dos recursos hídricos do domínio do Estado de São Paulo. O Decreto $N^{o}$ 50.667/2006 (SÃO PAULO, 2006), que regulamenta esta lei, determina a metodologia da cobrança e em seu Artigo 10 dispõe que o Preço Unitário Final (PUF) para captação, extração ou derivação deverá respeitar o limite máximo correspondente a 0,001078 UFESP por metro cúbico de água. O Decreto 60.302/14 (SÃO PAULO, 2014), através de seu Artigo 38, autoriza a cobrança pelo uso da água produzida nas UCs.

\section{MATERIAIS E MÉTODO}

\section{Caracterização da Area de Estudo}

O PESM é uma unidade de conservação de proteção integral criada em 30 de agosto de 1977 com a finalidade de assegurar integral proteção à flora, à fauna, às belezas naturais, bem como para garantir sua utilização a objetivos educacionais, recreativos e científicos (SÃO PAULO, 1977). Localizado na porção leste do Estado de São Paulo, ao longo da Serra do Mar, o PESM apresenta uma área de 3.153,90 km² e constitui-se em um verdadeiro corredor ecológico que conecta os mais significativos remanescentes de Mata Atlântica do país (SÃO PAULO, 2006b). A Figura 1 apresenta a localização do PESM no contexto do Estado de São Paulo. 
Figura 1. Localização do PESM no Estado de São Paulo.

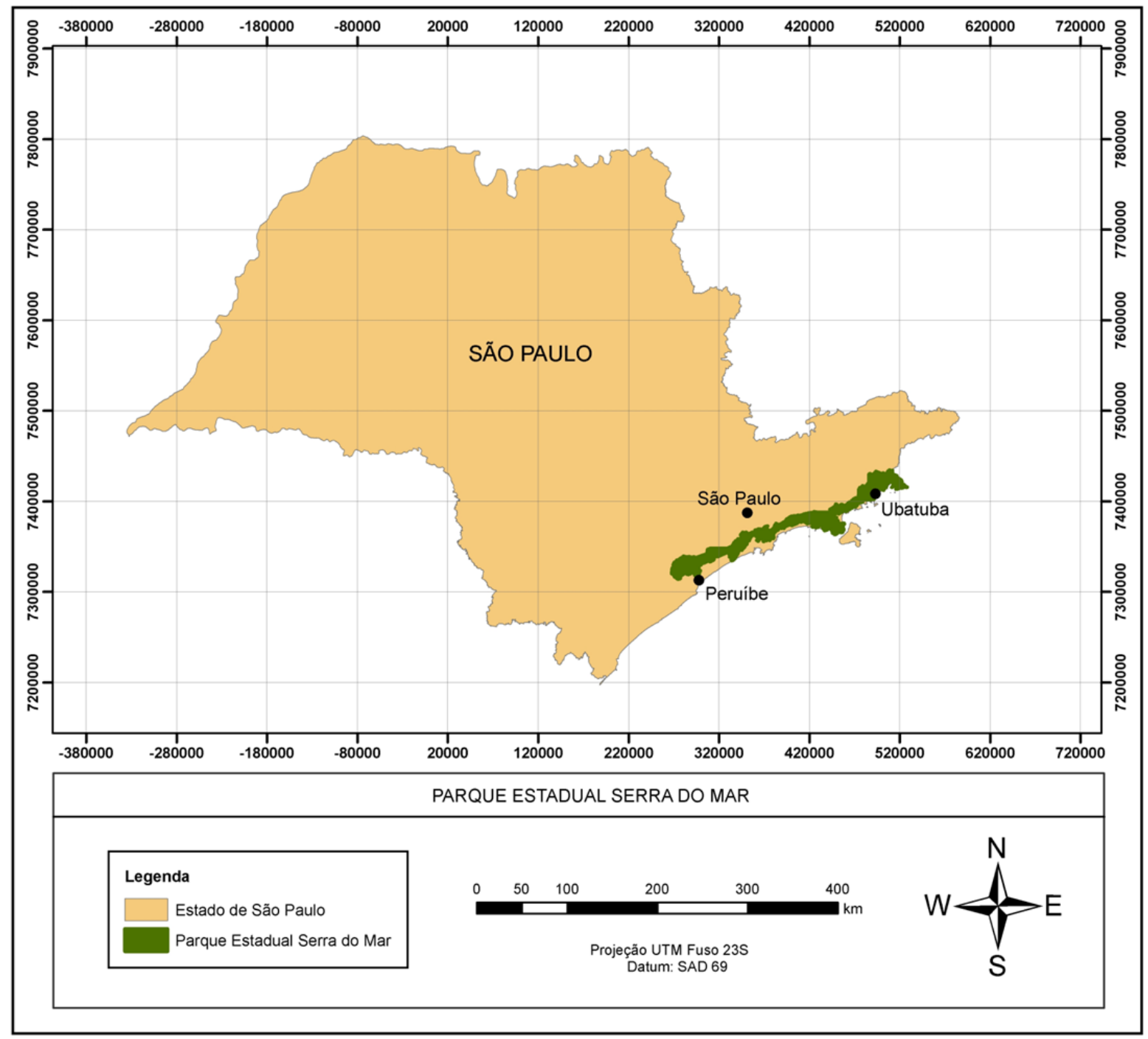

Fonte: STARZYNSKI, 2014

O território do PESM localiza-se em 23 municípios, sendo 11 na região litorânea (Ubatuba, Caraguatatuba, São Sebastião, Bertioga, Cubatão, Santos, São Vicente, Praia Grande, Mongaguá, Itanhaém, Peruíbe e Pedro de Toledo) e 12 na região do planalto (Cunha, São Luiz do Paraitinga, Natividade da Serra, Paraibuna, Salesópolis, Biritiba Mirim, Mogi das Cruzes, Santo André, São Bernardo do Campo, São Paulo e Juquitiba). Na ZA incluemse, além dos que apresentam área no interior da UC, os seguintes municípios: Embu-Guaçu, Guarujá, Itariri, Miracatu, Parati (RJ), Ribeirão Pires, Rio
Grande da Serra, São Lourenço da Serra e Suzano. A Figura 2 apresenta os 32 municípios que possuem áreas geográficas tanto no interior do PESM quanto em sua ZA. 
Figura 2. Municípios que possuem áreas geográficas no interior do PESM e ZA.

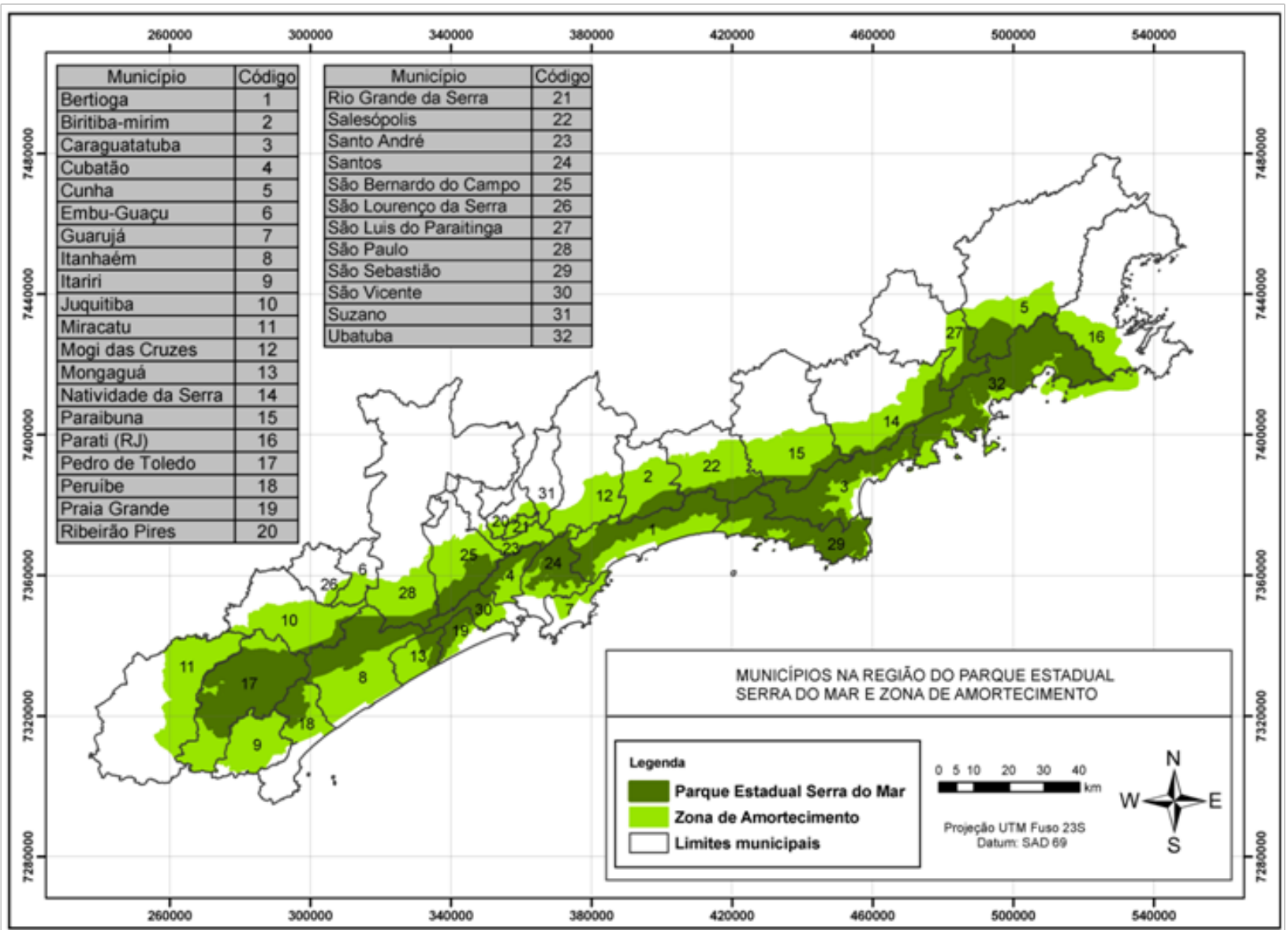

Fonte: STARZYNSKI, 2014

O PESM possui um Plano de Manejo (SÃO PAULO, 2006b), aprovado por Deliberação do Conselho Estadual do Meio Ambiente (CONSEMA, 2006), que constitui o principal instrumento de planejamento e avaliação das ações desenvolvidas na unidade de conservação; nele são apresentados o zoneamento da unidade de conservação, incluindo sua ZA, bem como as diretrizes de seus programas de manejo voltados ao Patrimônio Natural, Patrimônio Cultural, Interação Socioambiental, Proteção, Pesquisa, Uso Público e Gestão.

\section{Materiais empregados}

As informações referentes aos limites do PESM e de sua ZA foram extraídas do Plano de Manejo do PESM, obtido no site da Fundação para a Conservação e a Produção Florestal do Estado de
São Paulo (SÃO PAULO, 2006a). Estas informações também foram fornecidas pela referida instituição em formato digital, em arquivos de formato shapefile apropriados para utilização em programas de geoprocessamento. Nestes arquivos as informações encontram-se no Sistema de Projeção Universal Transversa de Mercator (UTM) e no Sistema Geodésico de Referência South American Datum 1969 (SAD 69).

Os dados de outorga de captação de água superficial e subterrânea em todos os municípios que apresentam área no PESM e ZA foram levantados junto ao Departamento de Águas e Energia Elétrica (DAEE), vinculado ao Governo do Estado de São Paulo. Os dados de outorga, para a área geográfica total de cada município, foram obtidos tanto a partir de planilhas fornecidas pelo próprio órgão quanto por pesquisas realizadas no site do DAEE. 
Junto ao Instituto Brasileiro de Geografia e Estatística (IBGE) foram obtidos os resultados dos Censos Demográficos realizados nos anos de 2000 e 2010, da mesma forma que dados municipais como áreas e limites geográficos (IBGE, 2000), (IBGE, 2010).

\section{Método de Pesquisa}

No presente trabalho foi definida como área de estudo a região abrangida pelo PESM e ZA em conformidade com o Plano de Manejo do PESM publicado no ano de 2006. É importante considerar que a proposta deste trabalho avaliar conjuntamente o interior do PESM e sua ZA, determinando nessas regiões tanto a pressão antrópica quanto a utilização atual dos recursos hídricos.

Com o objetivo de se conhecer a pressão demográfica sobre os recursos hídricos foram trabalhados dados populacionais divulgados pelo IBGE. A evolução da população residente nos municípios integrantes da região de estudo foi obtida a partir de dados dos Censos Demográficos de 2000 e 2010 .

Nesta pesquisa foram trabalhados dados de outorga de água que refletem o uso atual autorizado pelo órgão competente. Os dados de outorga de captação de água superficial e subterrânea na região de estudo foram calculados a partir de dados fornecidos pelo DAEE. Foram solicitados e fornecidos os dados de outorga de todos os municípios que apresentam área no PESM ou em sua Zona de Amortecimento. As planilhas eletrônicas, contendo os dado georreferenciados das captações, usuários e volumes outorgados, foram transformadas em shapefiles para utilização no software ArcGIS e, tendo por base os limites do PESM e Zona de Amortecimento, foram excluídos todos os dados de outorga localizados fora da área de estudo. Posteriormente, através da seleção por atributos (comandos Open Attribute Table / Options / Select By Attributes), os dados foram divididos em 6 categorias de usuários, a saber: Abastecimento público (código 1), Abastecimento privado (código 2), Uso rural (código 3), Uso industrial (código 4), Mineração (código 5), Serviços de engenharia e construção (código 6).
A seguir os dados foram exportados para planilha eletrônica na qual foram calculados os volumes outorgados. A categoria "Abastecimento público (código 1)" refere-se às captações da Companhia de Saneamento Básico do Estado de São Paulo (SABESP), empresa de economia mista, vinculada à Secretaria de Saneamento e Recursos Hídricos (SSRH), responsável pelo fornecimento de água, coleta e tratamento de esgotos em 364 municípios do Estado de São Paulo. A categoria "Abastecimento privado (código 2)" refere-se às soluções alternativas para o abastecimento de condomínios e associações diversas.

\section{RESULTADOS E DISCUSSÃO}

\section{Pressão demográfica na região de estudo}

Os municípios que possuem áreas geográficas no interior do PESM ou em sua Zona de Amortecimento apresentam grande variação de população e taxas de crescimento. No ano de 2010 os 10 municípios da UGRHI Alto Tietê apresentavam 13.609.653 habitantes, em grande parte pressionada pela população da cidade de São Paulo (11.253.503) que possui a parte sul do município no interior do PESM e em sua Zona de Amortecimento; na UGRHI Baixada Santista a população dos 9 municípios era de 1.664.136 habitantes; na UGRHI Litoral Norte a população era de 253.583 habitantes, que somada à população de Parati (Baia de Ilha Grande - RJ) totaliza 291.116 habitantes na parte norte da região de estudo; nos 5 municípios da UGRHI Ribeira de Iguape / Litoral Sul a população era de 88.977 habitantes; na UGRHI Paraíba do Sul, região de menor população, os 4 municípios totalizavam 56.329 habitantes. No total, em 2010, residiam 15.710.211 habitantes nos municípios que possuem área geográfica no interior do PESM e em sua Zona de Amortecimento. As taxas médias de crescimento anual da população, entre os anos de 2000 e 2010, nos municípios da região de estudo, compartimentada nas diversas UGRHIs, são apresentadas na Figura 3. 
Avaliação quantitativa do uso dos recursos hídricos em unidade de conservação: Estudo de caso do parque estadual Serra do Mar Roberto Starzynski, Silvio Jorge Simões

Figura 3. Taxas médias de crescimento anual da população, entre os anos de 2000 e 2010, nos municípios da região de estudo, compartimentada nas UGRHIs da Baixada Santista (A), Litoral Norte (B), Alto Tietê (C), Ribeirão do Iguape (D) e Paraíba do Sul (E).
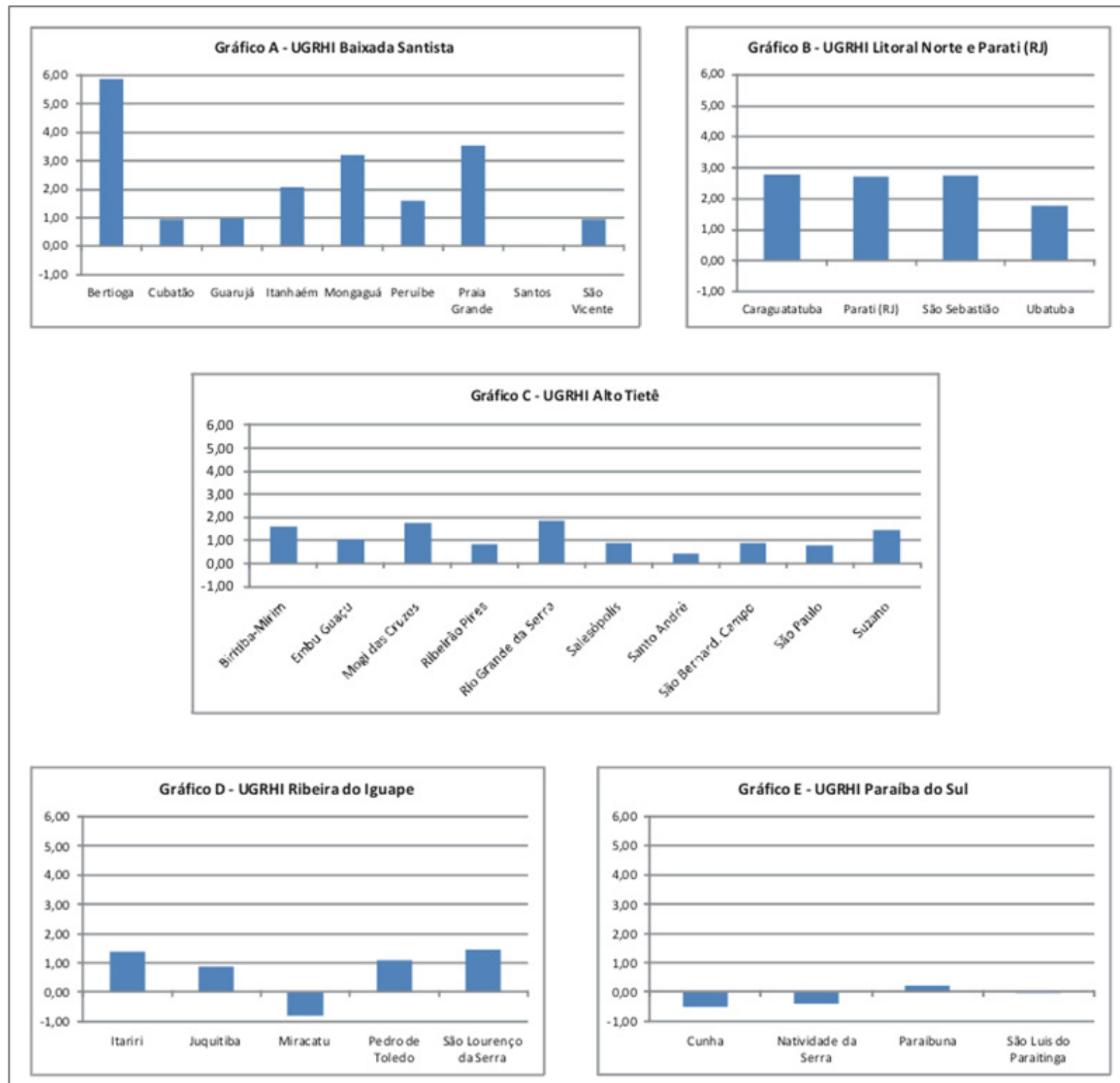

Fonte: STARZYNSKI, 2014

Considerando-se o período entre os anos de 2000 e 2010, a região que apresentou a maior taxa média de crescimento anual foi o Litoral Norte / Baia de Ilha Grande (2,50\%) seguida da Baixada Santista (2,14\%) e Alto Tietê (1,15\%). As menores taxas de crescimento foram verificadas nos municípios do Ribeira de Iguape / Litoral Sul
$(0,80 \%)$ e do Paraíba do Sul, que apresentou variação negativa (-0,18\%). Estes dados, comparados com a taxa média de crescimento anual dos municípios do Estado de São Paulo (1,01\%), mostram que as regiões do Litoral Norte, Baixada Santista e Alto Tietê apresentam grande população e elevadas taxas de crescimento anual. Este fato configura uma grande 
pressão sobre o PESM e ZA, especialmente sobre seus recursos hídricos, que são fundamentais para o desenvolvimento das atividades antrópicas na região de entorno da UC.

\section{Outorga de água na região de estudo}

Os dados do DAEE relativos à outorga de captação de água superficial e subterrânea permitiram a análise da distribuição espacial, bem como a quantificação da outorga de água na região de estudo. As Figuras 4 e 5 apresentam a distribuição dos pontos de captação em toda a região abrangida pelo PESM e ZA. Para efeito de representação gráfica a área de estudo foi dividida em Setor Sul e Setor Norte. É importante considerar que na escala dos mapas apresentados a seguir os pontos de captação muito próximos ficam superpostos, não se distinguindo entre si.

Figura 4. Distribuição das captações outorgadas pelo DAEE no Setor Sul

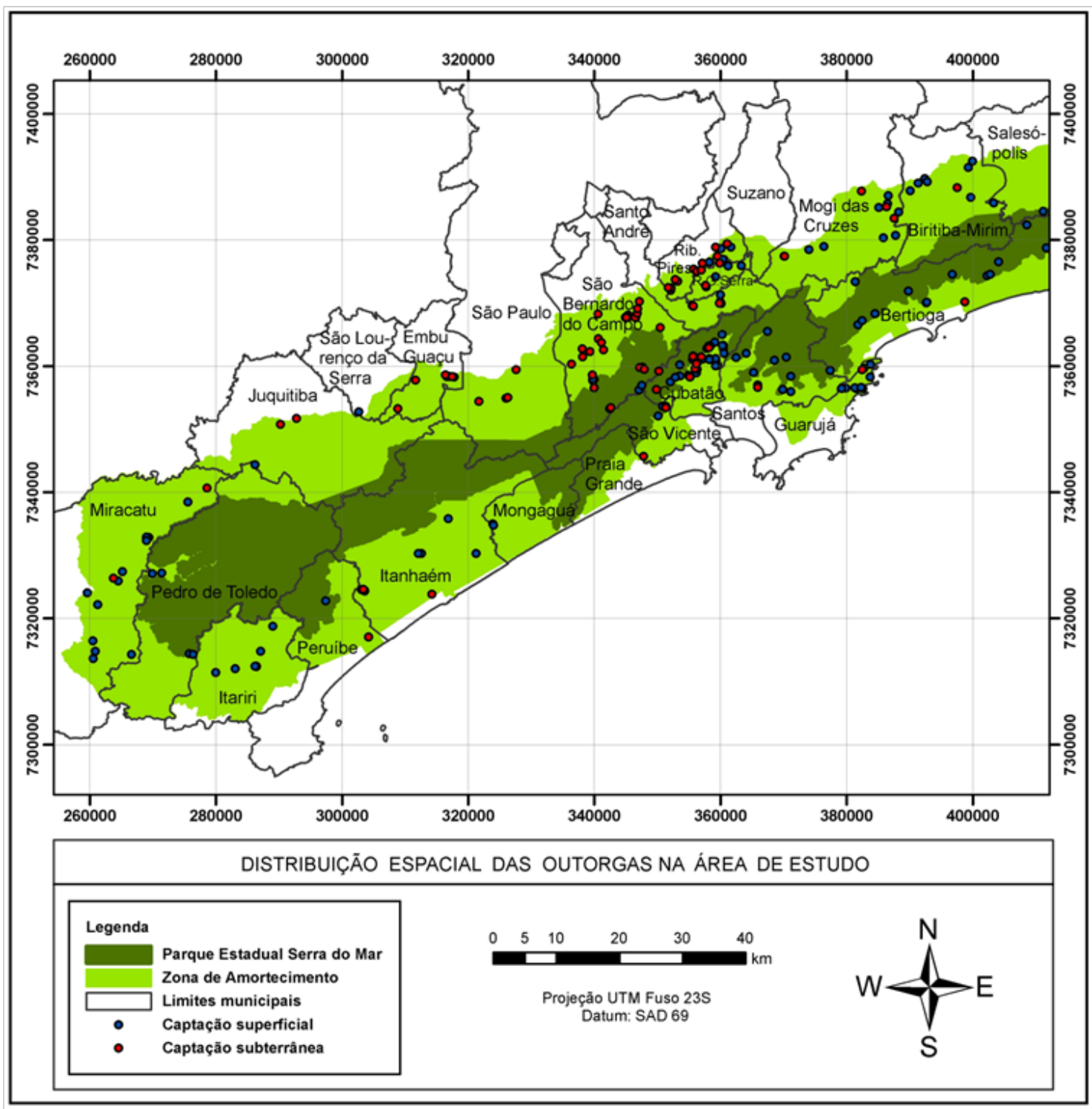

Fonte: Adaptado de STARZYNSKI, 2014 
$\mathrm{Na}$ região sudoeste do Setor Sul (Figura 4) predominam as captações na ZA do PESM; as captações superficiais destinam-se às atividades rurais, enquanto que as captações subterrâneas nos municípios de Embu-Guaçu e São Paulo destinamse, principalmente ao abastecimento público. No município de São Bernardo do Campo, ocorrem captações no interior do PESM, sendo as captações superficiais destinadas ao abastecimento público (SABESP) e captações subterrâneas destinadas à fins industriais (PETROBRAS) e serviços de engenharia e construção (concessionária ECOVIAS).

No município de Cubatão também ocorrem captações no interior do PESM sendo uma captação superficial outorgada para a PETROBRAS e uma captação para a concessionária ECOVIAS. As demais captações ocorrem na ZA, porém muito próximas aos limites do PESM, constituindo uma concentração na região em que a UC apresenta sua menor dimensão em largura (aproximadamente 2,0 $\mathrm{km})$. Este fato caracteriza a região como aquela que apresenta a maior pressão sobre os recursos hídricos do PESM. Os municípios de Ribeirão Pires e Rio Grande da Serra apresentam diversas captações na ZA, porém em reduzidos volumes, destinados principalmente ao uso industrial, enquanto que Mogi das Cruzes e Biritiba-Mirim apresentam captações na ZA destinadas principalmente ao uso rural.

Figura 5. Distribuição das captações outorgadas pelo DAEE no Setor Norte.

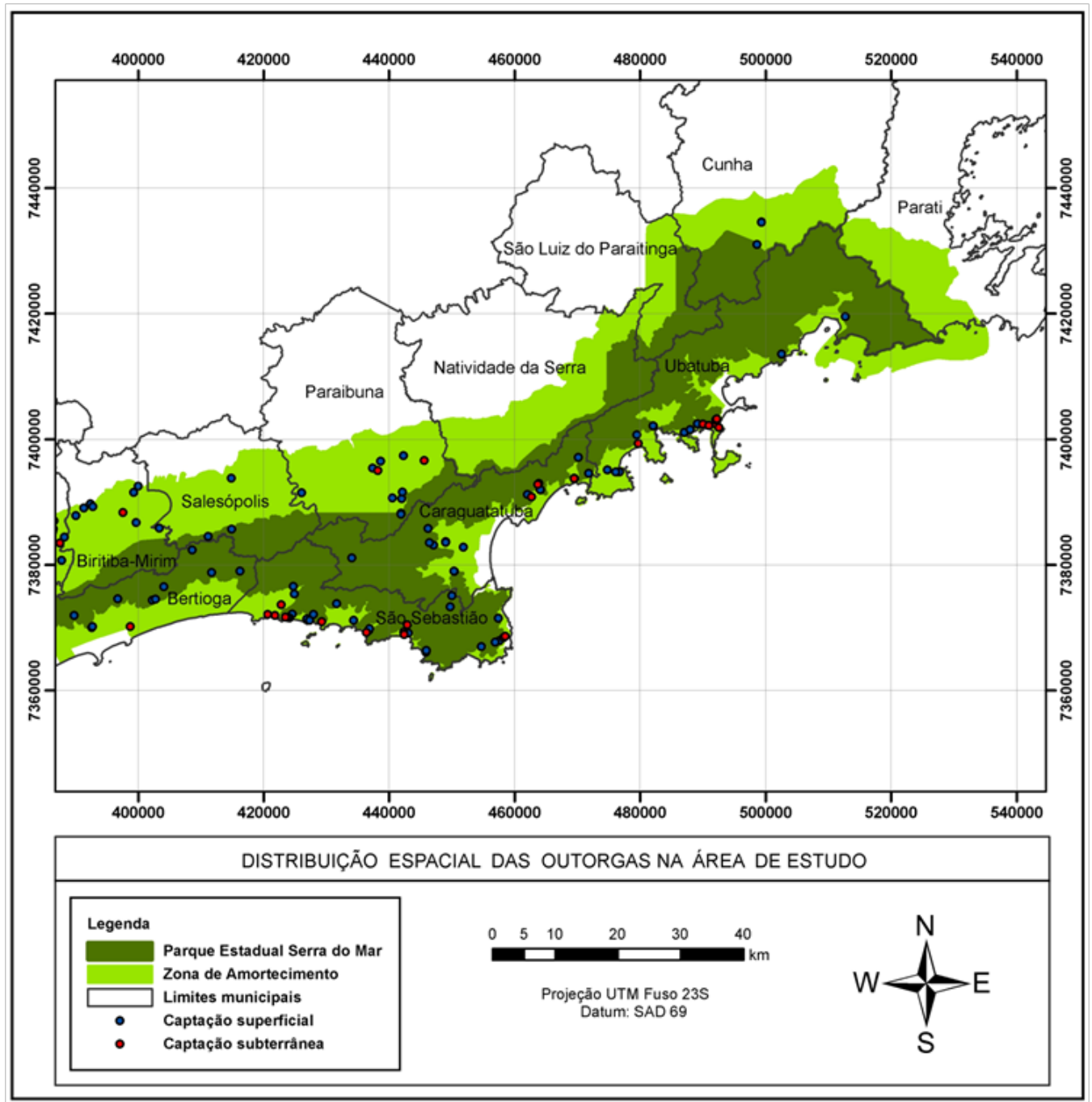

Fonte: Adaptado de STARZYNSKI, 2014 
No Setor Norte (Figura 5), no município de Salesópolis ocorrem captações superficiais destinadas ao abastecimento público localizadas nos limites do PESM enquanto que em Bertioga as captações ocorrem no interior do PESM e na Zona de Amortecimento, destinando-se, principalmente, ao abastecimento público e privado. Em São Sebastião as captações subterrâneas ocorrem na Zona de Amortecimento, sendo destinadas ao abastecimento privado e, na região do porto, estão associadas às atividades da Petrobrás. No interior do PESM ocorre uma captação superficial destinada ao abastecimento público enquanto que as demais localizam se na Zona se Amortecimento e destinam-se ao abastecimento público, privado, rural e industrial (Petrobrás). O município de Caraguatatuba apresenta no interior do PESM uma captação superficial para abastecimento público e outra para fins industriais (Petrobrás); na Zona de Amortecimento predominam as captações para abastecimento privado. No município de Paraibuna predominam as captações destinadas à serviços de engenharia e construção. No município de Ubatuba, ocorrem várias captações superficiais destinadas ao abastecimento público, localizadas nos limites do PESM; na Zona de Amortecimento predominam as captações, tanto superficiais quanto subterrâneas, destinadas ao abastecimento privado. No município de Cunha ocorrem duas captações superficiais para uso rural.
No interior do PESM e em sua ZA estão outorgadas 221 captações de água superficial, sendo 35 destinadas ao abastecimento público, 41 ao abastecimento privado, 63 para uso rural, 63 para uso industrial, 9 para mineração e 10 para serviços de engenharia e construção. O município de Cubatão é o que apresenta a maior quantidade de captações (41) bem como o maior volume outorgado (370.379.880 $\mathrm{m}^{3} / \mathrm{ano}$ ) que representa $49,68 \%$ das outorgas superficiais na área de estudo. Na mesma região estão outorgadas 159 captações de água de água subterrânea, sendo 14 destinadas ao abastecimento público, 34 ao abastecimento privado, 12 para uso rural, 83 para uso industrial, 5 para mineração e 11 para serviços de engenharia e construção. Os municípios de São Bernardo do Campo (30 captações, $2.000 .652 \mathrm{~m}^{3} / \mathrm{ano}$ ) e Embu-Guaçu (9 captações, $1.531 .080 \mathrm{~m}^{3} /$ ano) são os que apresentam o maior volume de captações, sendo responsáveis por $51,86 \%$ das outorgas subterrâneas na área de estudo.

Os dados dos volumes outorgados para cada categoria de usuário são apresentados na Tabela 1. Para cada tipo de captação (superficial e subterrânea) apresenta o volume e a porcentagem do volume em relação ao total outorgado para cada tipo de captação. Da mesma forma a coluna referente à outorga total apresenta o volume total e a porcentagem da outorga de cada categoria em relação ao volume total outorgado na região de estudo (752.305.722 $\left.\mathrm{m}^{3} / \mathrm{ano}\right)$.

Tabela 1. Captações de água outorgadas pelo DAEE no interior do PESM e na ZA.

\begin{tabular}{|c|c|c|c|c|c|c|c|}
\hline \multirow[t]{2}{*}{ Categoria } & \multirow[t]{2}{*}{$\begin{array}{l}\text { Cód. } \\
\text { Uso }\end{array}$} & \multicolumn{2}{|c|}{$\begin{array}{l}\text { Captação } \\
\text { Superficial }\end{array}$} & \multicolumn{2}{|c|}{ Captação Subterrânea } & \multicolumn{2}{|c|}{$\begin{array}{c}\text { Captação } \\
\text { Total }\end{array}$} \\
\hline & & $\left(\mathrm{m}^{3} / \mathrm{ano}\right)$ & $(\%)$ & (mªno) & $(\%)$ & $\left(\mathrm{m}^{3} / \mathbf{a n o}\right)$ & $(\%)$ \\
\hline Abastecimento público & 1 & 480.720 .301 & 64,48 & 3.762 .720 & 55,25 & 484.483 .021 & 64,40 \\
\hline Abastecimento privado & 2 & 23.691 .232 & 3,18 & 582.126 & 8,55 & 24.273 .358 & 3,23 \\
\hline Uso rural & 3 & 19.716 .685 & 2,64 & 33.445 & 0,49 & 19.750 .130 & 2,63 \\
\hline Uso industrial & 4 & 220.348 .357 & 29,56 & 2.172 .743 & 31,90 & 222.521 .100 & 29,58 \\
\hline Mineração & 5 & 317.430 & 0,04 & 222.984 & 3,27 & 540.414 & 0,07 \\
\hline Eng. e construção. & 6 & 701.087 & 0,09 & 36.612 & 0,54 & 737.699 & 0,10 \\
\hline TOTAL & & 745.495 .092 & 100,00 & 6.810 .630 & 100,00 & 752.305 .722 & 100,00 \\
\hline
\end{tabular}

Fonte: Adaptado de STARZYNSKI, 2014 
Ao se analisar os dados de captação superficial verifica-se que o abastecimento público é responsável pela maior parcela $(64,48 \%)$ da captação seguido pelo setor industrial $(29,56 \%)$. Ao se analisar os dados de captação subterrânea verifica-se também que o abastecimento público é responsável pela maior parcela $(55,25 \%)$ da captação seguido pelo setor industrial $(31,90 \%)$.

Ao se observar os dados do volume total outorgado constata-se que o Abastecimento público é a categoria que apresenta o maior volume $(64,40 \%)$, seguido pelo Uso industrial (29,58\%), Abastecimento privado $(3,23 \%)$, Uso rural $(2,63 \%)$, Serviços de engenharia e construção $(0,10 \%)$ e Mineração $(0,07 \%)$. A análise dos volumes totais outorgados mostra também que $99,09 \%$ da água é captada superficialmente e apenas $0,91 \%$ captada em poços.

\section{CONCLUSÕES}

No interior do PESM e em sua ZA estão localizados 32 municípios que apresentam grande variação de população e taxas de crescimento. Algumas regiões, como a Baixada Santista e o Litoral Norte, apresentaram entre os anos de 2000 e 2010 taxas médias de crescimento anual superior a 2,00\%, valor acima da média estadual de 1,01\%. Este fato configura uma grande pressão sobre a UC, especialmente sobre seus recursos hídricos, que são fundamentais para 0 desenvolvimento das atividades antrópicas na região de entorno.

Os dados relativos à outorga de água mostram que no interior do PESM e em sua ZA estão outorgadas 221 captações de água superficial que totalizam um volume de $745.495 .092 \mathrm{~m}^{3} /$ ano. O município de Cubatão é o que apresenta a maior quantidade de captações (41) bem como o maior volume outorgado $\left(370.379 .880 \mathrm{~m}^{3} /\right.$ ano) que representa $49,68 \%$ das outorgas superficiais na área de estudo. Na mesma região estão outorgadas 159 captações de água subterrânea que totalizam um volume de $6.810 .630 \mathrm{~m}^{3} / \mathrm{ano}$. Os municípios de São Bernardo do Campo (30 captações, 2.000 .652 m³/ano) e Embu-Guaçu ( 9 captações, $1.531 .080 \mathrm{~m}^{3} /$ ano) são os que apresentam o maior volume de captações, sendo responsáveis por $51,86 \%$ das outorgas subterrâneas na área de estudo. A análise dos volumes totais outorgados mostra que $99,09 \%$ da água é captada superficialmente e apenas $0,91 \%$ captada em poços. Isto demonstra a importância dos processos hidrológicos superficiais na captação de água e reforça a importância da manutenção da integridade florestal para os diversos usuários da água que verte do PESM. Os dados de outorga mostram também que o Abastecimento público é a categoria que apresenta o maior volume $(64,40 \%)$, seguido pelo Uso industrial (29,58\%), Abastecimento privado (3,23\%), Uso rural (2,63\%), Serviços de engenharia e construção $(0,10 \%)$ e Mineração $(0,07 \%)$.

A grande utilização dos recursos hídricos do PESM é um forte argumento para a implantação de uma política de PSA, que venha a garantir a continuidade da produção de água através do aumento das ações de proteção da UC, em função de um maior aporte de recursos financeiros a ser realizado pelos usuários. $\mathrm{O}$ pagamento pelos serviços ambientais prestados por uma UC é matéria que ainda carece de estudos e propostas de parâmetros que possam nortear a compensação ambiental. No caso do uso pelos recursos hídricos parece lógico indexar o valor da compensação à quantidade $\mathrm{e}$ qualidade da água utilizada. Este trabalho colabora com a avaliação quantitativa do uso dos recursos hídricos do PESM e ressalta que o aspecto qualitativo também precisa ser valorado, pois a manutenção da cobertura florestal natural proporciona uma água com baixo teor de sedimentos, o que reduz consideravelmente os custos operacionais das Estações de Tratamento de Água.

Este trabalho também constatou que a concentração da demanda em setores de grande consumo, como o abastecimento público e uso industrial, é um fator positivo para a implantação dessa política, ao facilitar a identificação do usuário e o controle da arrecadação.

\section{REFERÊNCIAS}

ALBIZU, O. O.; HIDALGO, M. M. O.; MADRIGAL, O. Q. \& ARREGUI, J. L. Servicios ambientales del bosque: ensayo en una cuenca atlántica europea con base en la experiencia de Centroamérica. Revista de Biologia Tropical, San José dic, v.56, n.2, 2008.

ARCOVA, F. C. S. Balanço hídrico, características do defluvio e calibragem de duas microbacias hidrográficas 
na Serra do Mar, SP. 1996. 130 f. Dissertação de Mestrado. Escola Superior de Agricultura Luiz de Queiroz - USP, Piracicaba.

ARCOVA, F. C. S.; CICCO, V. de. Qualidade da água de microbacias com diferentes usos do solo na região de Cunha, Estado de São Paulo. Scientia Forestalis, Piracicaba, 56: 125-134, 1999.

BRAGA, B.; PORTO, M.; TUCCI, C. Monitoramento de Quantidade e Qualidade das Águas. In: REBOUÇAS (Org.). Águas Doces no Brasil: Capital Ecológico, Usos e Conservação. São Paulo: Editora Escrituras, 2002. p. 635-649.

BRASIL. Lein. 9.985, de 18 de julho de 2000. Regulamenta o art. 225, § 1o, incisos I, II, III e VII da Constituição Federal, institui o Sistema Nacional de Unidades de Conservação da Natureza e dá outras providências. Disponível em: $<$ http:// www.planalto.gov. br/ccivil_03/leis/19985.htm>. Acesso em: 4 jul. 2013.

CARVALHO, J.L.; CICCO, V. de; FUJIEDA, M. 1992. Algumas propriedades físicas dos solos da bacia hidrográfica "D" no Núcleo Cunha-SP. In: CONGRESSO NACIONAL SOBRE ESSÊNCIAS NATIVAS, 2:;1992, São Paulo.Anais... Revista do Instituto Florestal, São Paulo 1992. p. 753-759.

CICCO, V. de; ARCOVA, F. C. S.; SHIMOMICHI, P. Y.; FUJIEDA, M. Interceptação das chuvas por floresta natural secundária de Mata Atlântica - São Paulo. Silvicultura em São Paulo, São Paulo, 20/22, p. 25-30, 1986.

CONSEMA. Deliberação 34/2006. Aprova o Plano de Manejo do Parque Estadual da Serra do Mar. Disponível em: $<$ http://fflorestal.sp.gov.br/files/2012/01/Del34 SerradoMar. pdf $>$. Acesso em: 8 jan. 2014.

DEPARTAMENTODEÁGUAEENERGIAELÉTRICA. Pesquisa de dados dos recursos hídricos do Estado de São Paulo. Disponível em $<\mathrm{http}: / / \mathrm{www}$.aplicacoes.daee .sp.gov. br/usosrec/fchweb.html>. Acesso em: 7 mai. 2013.

FELL, E. T.; TREMÉA, E. M. O princípio do ProtetorRecebedor e o Proambiente: Limites e possibilidade da compensação financeira. Âmbito Jurídico, Rio Grande, XI, n. 51, mar. 2008.

FLORES, R. S. ; VERDÍN, G. P. ; CHÁIDEZ, J. J. $\mathrm{N}$. Valoración económica de los servicios ambientales hidrológicos en El Salto, Pueblo Nuevo, Durango. Madera y bosques. Xalapa, v. 16, n.1, 2010.

FUJIEDA, M.; KUDOH, T.; CICCO, V. de; CARVALHO, J. L. Hydrological processes at two subtropical forest catchments: the Serra do Mar, São Paulo, Brazil. Journal of Hydrology, Amsterdam, v. 196, p. 26-46, 1997. DOI:10.1016/S0022-1694(97)00015-2

HONDA, E.A.;ARCOVA, F. C. S.; CICCO, V.de;ANIDO, N. M. R. Concentração de sedimentos em suspensão em rios de bacias com diferentes usos do solo, na região do Alto Paraiba - SP. In: ENCONTRO NACIONAL DE ENGENHARIA DE SEDIMENTOS, 5. 2002, São Paulo. Anais...São Paulo: ABRH, 2002. p. 395-401.

HUPFFER, H. M.; WEYERMULLER, A. R.; WACLAWOVSKY, W. G. Uma análise sistêmica do princípio do protetor - recebedor na institucionalização de programas de compensação por serviços ambientais. Ambiente \& Sociedade, São Paulo, v.14, n.1, jan./ jun. 2011. DOI: http://dx.doi.org/10.1590/S1414753X2011000100006

INSTITUTO BRASILEIRO DE GEOGRAFIA E ESTATÍSTICA. Censo Demográfico 2000. Disponível em: <http://www.ibge.gov.br/home/estatistica/populacao/ censo2000 /ufs.php?tipo=31o/tabela13_1.shtm $>$. Acesso em: 2 out. 2013.

INSTITUTO BRASILEIRO DE GEOGRAFIA E ESTATÍSTICA. Censo Demográfico 2010. Características da População e dos Domicílios. 2011. Disponível em: $<\mathrm{ftp}$ //geoftp.ibge.gov.br/malhas_digitais/censo_2010/ setores_censitarios/>, $<\mathrm{ftp}$ ://ftp.ibge.gov.br/Censos/ Censo_Demografico_2010/Resultados_do_Universo/ Agregados_por_Setores_Censitarios/ >.Acesso em: 4 jul. 2013.

LIMA, W. deP. OPapel Hidrológico daFloresta na Proteção dos Recursos Hídricos. CONGRESSO FLORESTAL 
BRASILEIRO, 1. 1986, Olinda. Revista Silvicultura, v.41, p. 59-62.

POLANCO, G. A.; SOBERANIS, L. H.; DIÉGUES, E. T.; AMADOR, B. M.; HERNÁNDEZ, J. L. G.; MORALES, L. F. B. Valoración económica del servicio hidrológico del acuífero de La Paz, B.C.S.: Una valoración contingente del uso de agua municipal. Frontera norte, México, v.22 n.43 ene./jun. 2010.

REIS, L. V. de S. Cobertura Florestal e Custo do Tratamento de Águas em Bacias Hidrográficas de Abastecimento Público: Um Caso do Manancial do Município de Piracicaba. 2004. 215f. Tese ( Doutorado em Recursos Florestais) - Escola Superior deAgricultura Luiz de Queiroz, Universidade de São Paulo, Piracicaba.

SANTOS, J. E.; NOGUEIRA, F. ; PIRES, J. S. R. ; OBARA, A. T. \& PIRES, A. M. Z. C. R. The value of the Ecological Station of Jataí's ecosystem services and natural capital. Revista Brasileira de Biologia, São Carlos, v.61, n.2, mai. 2001. DOI: http://dx.doi.org/10.1590/S003471082001000200002

SÃO PAULO (Estado). Decreto $N^{o}$. 10.251, de 30 de agosto de 1977. Cria o Parque Estadual da Serra do Mar e dá providências correlatas. Disponível em: $<$ http://governosp.jusbrasil.com.br/legislacao/211617/decreto-10251-77>. Acesso em: 4 jul. 2013.

SÃO PAULO (Estado). Lei $N^{o} 7.663$, de 30 de dezembro de 1991. Estabelece normas de orientação à Política Estadual de Recursos Hídricos bem como ao Sistema Integrado de Gerenciamento de Recursos Hídricos. Disponível em: < http:/governo-sp.jusbrasil.com.br/ legislacao/180981/lei7663-91>. Acesso em: 4 jul. 2013.

SÃO PAULO(Estado). Lei $N^{\circ} 9.034$, de 27 de dezembro de 1994 . Dispõe sobre o Plano Estadual de Recursos Hídricos - PERH, a ser implantado no período 1994 e 1995, em conformidade com a Lei no 7663 , de 30 de dezembro de 1991, que instituiu normas de orientação à Política Estadual de Recursos Hídricos. Disponível em: < http://governo-sp. jusbrasil.com.br/legislacao/174303/lei-9034-94 > . Acesso em: 4 jul. 2013.
SÃOPAULO(Estado). Lei $N^{\circ} 12.183$, de 29 de dezembro de 2005. Dispõe sobre a cobrança pela utilização dos recursos hídricos do domínio do Estado de São Paulo. Disponível em: < http:/governo-sp.jusbrasil.com.br/legislacao/91946/ lei-12183-05 >. Acesso em: 4 jul. 2013.

SÃO PAULO(Estado). Decreto $N^{\circ} 50.667$, de 30 de março de 2006. Regulamenta dispositivos da Lei no 12.183 de 29 de dezembro de 2005, que trata da cobrança pela utilização dos recursos hídricos do domínio do Estado de São Paulo, e dá providências correlatas. Disponível em: $<$ http://governosp.jusbrasil.com.br/legislacao/92538/decreto-50667-06 >. Acesso em: 4 jul. 2013.

SÃO PAULO (Estado). Secretaria do Meio Ambiente. Instituto Florestal. Plano de Manejo do Parque Estadual da Serra do Mar. São Paulo, 2006. Disponível em: $<$ http:// fflorestal.sp.gov.br/planos-de-manejo/planos-de-manejoplanos-concluidos/>. Acesso em: 4 jul. 2013.

SÃO PAULO(Estado). Decreto n ${ }^{\circ}$ 60.302, de 27 de Março de 2014. Institui o Sistema de Informação e Gestão de Áreas Protegidas e de Interesse Ambiental do Estado de São Paulo-SIGAPe dá providências correlatas. Disponível em: $<$ http://governo-sp.jusbrasil.com.br/ legislacao/114664863/ decreto-60302-14-sao-paulo-sp >. Acesso em: 15 abr. 2014.

VINICIO, M. Financiamiento de bosques y plantaciones forestales: pago por servicios ambientales. Revista Forestal Centroamericana, Turrialba v. 22, p. 13-20, 1998.

WWF BRASIL. Unidades de conservação: conservando a vida, os bens e os serviços ambientais. São Paulo, 2008. Disponível em: $<$ http://d3nehc6yl9qzo4.cloudfront. net/ downloads/cartilha_ucs_versao_para_internet.pdf $>$ Acesso em: 13 mar. 2014.

STARZYNSKI, R. Avaliação quantitativa do uso dos recursos hídricos em unidade de conservação e entorno. Estudo de caso do Parque Estadual da Serra do Mar. 2014. 79f. Dissertação de mestrado. UNESP, Guaratinguetá. 